Disclosure of Interest: None declared

DOI: 10.1136/annrheumdis-2018-eular.2154

\section{AB0267 BASELINE PREDICTORS OF RESPONSE TO METHOTREXATE IN EARLY RHEUMATOID ARTHRITIS}

S. Rizvi, M. Bukhari. Rheumatology, Royal Lancaster Infirmary, Lancaster, UK

Background: The disease activity score (DAS28) is widely used to assess response to treatment in early rheumatoid arthritis. Few studies have looked at the individual components of the DAS at baseline to predict drop in DAS28 in early disease. Specifically at 3, 6 and 12 months. Predicting response early in disase would enable more targetted treatments to be given and patients selecteed early for more aggressive disease control. Although certain biomarkers have been advocated for use and have shown some promise. ${ }^{1,2}$ there is still a place for exploring using more clinically derived indicators.

Objectives: To determine whether DAS28 response at 3,6 and 12 months could be predicted by baseline components of the DAS28

Methods: The study used patients from the multicentre UK based RAMS study. All patients with early rheumatoid arthritis starting methotrexate were enrolled. We used data from a single centre in the North west of England for the analysis. DAS28 and it's components were recorded at baseline and at 36 and 12 months. Baseline components of the DAS28 were used to predict the change in DAS from baseline to 36 and 12 months. Linear regression was used with subsequent adjustment for age and gender.

Results: 120 patients were enrolled in the study, median age was 62.4 years (IQR42.1, 72.5), 81 (67\%) were female. Median das28 at baseline was 5.3 (IQR $4.2,6.2$ ). Duration of symptoms was 9 months (IQR 2,11). There was a drop of DAS28 of 1.49 at 3 months (IQR $0.57,2.45$ ) and at 6 and 12 months it was 1.84 (IQR $0.48,2.91$ ) and 1.63 (IQR $0.72,2.85$ ) respectively. At three months the only baseline predictor of change in DAS28 was the patient global assessment unadjusted and adjusted for age adjusted beta $0.01295 \% \mathrm{Cl} 0.002,0.023(\mathrm{p}=0.02)$. At six months the baseline tender joint count adjusted beta $0.0895 \% \mathrm{Cl} 0.015$, $0.154(\mathrm{p}=0.01)$ as well as swollen joint count adjusted beta $0.0595 \% \mathrm{Cl}$ $0.004,0.095(p=0.02)$ also predicted reposnse in addition to the patients global assessment adjusted beta $0.01695 \% \mathrm{Cl} 0.002,0.03(\mathrm{p}=0.01)$, but not the ESR or CRP at baseline $(p=N S)$. At 12 months the only predictors of response was the baseline CRP adjusted beta $0.0295 \% \mathrm{Cl} 0.005,0.04(\mathrm{p}=0.02)$.

Conclusions: In this cohort of patients with early disease, response to methotrexate could not be reliably predicted using baseline measures and the ability to predcit patients who would improve could not be found in this cohort. Further work on other clinical biomarkers to predict response is needed.

\section{REFERENCES:}

[1] Arthritis Res Ther. 2016 Feb 1;18:37.

[2] Rheumatology (Oxford). 2017 Jun 1;56(6):973-980.

Disclosure of Interest: None declared

DOI: 10.1136/annrheumdis-2018-eular.5538

\section{AB0268 HOW DO PATIENTS WITH RHEUMATOID ARTHRITIS EVALUATE THEIR GLOBAL ASSESSMENT?}

M. Kojima ${ }^{1}$, T. Kojima ${ }^{2}$. ${ }^{1}$ Medical Education, Nagoya City University Graduate School of Medical Sciences; ${ }^{2}$ Orthopedic Surgery, Nagoya University Hospital, Nagoya, Japan

Background: The importance of patient-reported outcomes (PRO) has been recently recognised. Patient global assessment (PtGA) is one of the most popular PROs in rheumatology. However, the validity of PtGA as a tool for assessment of disease activity and its relevance compared with other tools is still debated. ${ }^{1}$ Patients' perspective is essential to achieve treat-to-target. The significance of measuring PtGA in clinical practice should be verified. We previously found that Japanese rheumatologists changed their strategy to ask patient global assessment (PtGA) according to the patients' understanding ability. It is unknown how patients themselves feel PtGA.

Objectives: To investigate how patients with rheumatoid arthritis (RA) evaluate and accept PtGA as assessment tool of RA activity.

Methods: During the period of , August and September, 2016 a 90 min focus group was held four times. Nine or 10 RA patients participated in each focus group. Totally, 34 women and 4 men, average age $56.1 \pm 10.9$ years old, and disease history 9.39 \pm 9 . 36 years joined the study. The participants freely discussed how to evaluate their conditions of rheumatism and therapeutic effect. We used the "Steps for Coding and Theorization" (SCAT) ${ }^{2-3}$ to analyse the focus group data.

Results: Patients determined their PtGA based on pain, swelling, inconvenience of daily life, the mood of the day, comprehensively, although they felt confusing because the criteria of how to evaluate PtGA was unclear. Most patients set 100 of PtGA as "when most painful after onset", while standard of 0 was varied. Many patients had experienced a discrepancy between PtGA and CRP that their doctors denied. Patients were eager that their doctor would understand the discordance between PtGA and laboratory data and ask the patients "what's wrong with you?"

Conclusions: Doctors and patients should discuss how to evaluate PtGA at the start of treatment to avoid patients' confusing. By utilising PtGA as a communication tool, relationship between doctor and patients would be facilitated.

\section{REFERENCES :}

[1] Kojima M, Kojima T, Suzuki S, Takahashi N, Funahashi K, Asai S, Yoshioka Y, Terabe K, Asai N, Takemoto T, Ishiguro N. Patient-reported outcomes as assessment tools and predictors of long-term prognosis: a 7year follow-up study of patients with rheumatoid arthritis. Int J Rheum Dis. 2017;20(9):1193-1200.

[2] Otani T. "SCAT" A qualitative data analysis method by four-setp coding: Easy startable and small scale data-applicable process of theorization. Bulletin of the Graduate School of Education and Human Development (Educational Sciences), Nagoya University 2007;54:27-44.

[3] Kojima M, Nakayama T, Otani T, Hasegawa M, Kawahito Y, Kaneko Y, Kishimoto M, Hirata S, Seto Y, Endo H, Ito H, Kojima T, Nishida K, Matsushita I, Tsutani K, Igarashi A, Kamatani N, Miyasaka N, Yamanaka H. Integrating patients' perceptions into clinical practice guidelines for the management of rheumatoid arthritis in Japan. Mod Rheumatol. 2017;27 (6):924-929.

Disclosure of Interest: None declared

DOI: 10.1136/annrheumdis-2018-eular.2662

\section{AB0269 ANKLE SYNOVITIS AND TREAT-TO-TARGET STRATEGY IN CLINICALLY AND SEROLOGICALLY DIFFERENT FORMS OF RHEUMATOID ARTHRITIS, A SINGLE- CENTRE EXPERIENCE}

M. Kedves $^{1}$, J. Gál ${ }^{1}$, K. Törőcsik ${ }^{1}$, D. Balaton ${ }^{1}$, J. Csitos ${ }^{1}$, N. Megyes ${ }^{1}$, G. Nagy ${ }^{2}$. ${ }^{1}$ Rheumatology, Bacs-Kiskun County Hospital, Kecskemét; ${ }^{2}$ Rheumatology, Semmelweis University, Budapest, Hungary

Background: DAS28 based treat-to-target (T2T) strategy ${ }^{1}$ was shown to improve outcomes in patients with rheumatoid arthritis (RA). Although previous studies have shown that approximately $1 / 3$ of RA patients have foot symptoms $\left[{ }^{2}\right.$ ankle and foot joints are not included in DAS28.

Objectives: To study the prevalence of ankle synovitis in clinically and serologically different forms of RA, treated according to the updated T2T strategy.

Methods: 1109 patients, with RA, treated according to the T2T approach were included in this study. Concurrent tenderness and swelling of the ankle joint were considered as synovitis. Rheumatoid factor (RF) and anti-mutated citrullinated vimentin (anti-MCV) positive and negative patients with different disease activity were evaluated

Results: $8.47 \%$ (94) patients had high (DAS28 >5.1); 35.25\% (391) moderate (DAS28 $\leq 5.1 ;>3.2$ ) and $18.66 \%$ (207) low (DAS28 $\leq 3.2 ; \geq 2.6$ ) disease activity. $37,6 \%(417)$ of patients were in clinical remission (DAS28 $<2.6$ ). $60.71 \%{ }^{17}$ of antiMCV and RF positive and $44.8 \%{ }^{13}$ of anti-MCV and RF negative patients with high disease activity had ankle synovitis (table 1). Regarding patients in remis sion, $13.7 \%{ }^{18}$ of anti-MCV and RF positive and $15 \%{ }^{18}$ of anti-MCV and RF negative patients had ankle synovitis (table 2). Interestingly, ankle synovitis was considerably more common than knee synovitis in all patient groups.

Abstract AB0269 - Table 1. Ankle and knee involvement in high disease activity

\begin{tabular}{lccc}
\hline & $\begin{array}{c}\text { DAS28 }>5,1 . \\
94 \text { patients } \\
\text { in total }\end{array}$ & $\begin{array}{c}\text { DAS28>5,1. RF pos., } \\
\text { anti-MCV pos: } \\
28 \text { patients }\end{array}$ & $\begin{array}{c}\text { DAS28>5,1. RF neg, } \\
\text { anti-MCV neg: } \\
29 \text { patients }\end{array}$ \\
\hline Right knee synovitis & $21,27 \%$ & $25 \%$ & $24,13 \%$ \\
Left knee synovitis & $19,14 \%$ & $25 \%$ & $10,31 \%$ \\
Both knees synovitis & $4,25 \%$ & $10,71 \%$ & 0 \\
$\%$ of patients with knee & $36,17 \%$ & $39,28 \%$ & $34,48 \%$ \\
involvement & & & \\
Right ankle synovitis & $31,91 \%$ & $28,57 \%$ & $34,48 \%$ \\
Left ankle synovitis & $37,23 \%$ & $42,85 \%$ & $44,82 \%$ \\
Both ankles synovitis & $13,82 \%$ & $10,71 \%$ & $34,48 \%$ \\
$\%$ of patients with ankle & $55,31 \%$ & $60,71 \%$ & $44,82 \%$ \\
involvement & & &
\end{tabular}

